\title{
SISTEM MANAJEMEN PENGELOLAAN HUTAN FSC, PEFC, ISO 38200:2018 DAN PENGARUHNYA TERHADAP KINERJA INDUSTRI KAYU DI INDONESIA
}

(Forest Management System Of Fsc, Pefc, Iso 38200: 2018 And Its Effect On The Performance of Wood Industry In Indonesia)

\author{
Agus Purwanto ${ }^{1 *}$, Rudy Pramono ${ }^{1)}$, Mirza Prameswari ${ }^{1)}$, Masduki Asbari ${ }^{1)}$ \\ ${ }^{1)}$ Universitas Pelita Harapan, Tangerang, Indonesia \\ E-mail: agozpor@gmail.com
}

\begin{abstract}
The purpose of this study was to determine the effect of FSC Chain of Custody forest management, PEFC Sustainable Forest Management and ISO 38200 Chain of wood custody and wood-based products on the performance of the wood industry business in Indonesia performance indicators namely customer satisfaction, increased sales and productivity. This research was conducted in several companies that process wood or use wood as the main material in Indonesia with 400 respondents. Respondents are wood industry employees as top management, managers and staff who have a planor have implemented FSC, PEFC and ISO 38200. The background of this study is due to the lack of PEFC, FSC and ISO 38200 research on wood in Indonesia. Data collection was carried out by distributing electronic online questionnaires in August to November 2019 and analyzing data processing using Structural Equation Model (SEM) and Linear Structural Model (LISREL) software version 8.70. The results of the analysis show that FSC Chain of Custody, PEFC Sustainable Forest Management and ISO 38200 Chain of custody from wood and wood-based affect the business significantly and positively such as increased customer satisfaction, increased sales and increased productivity.
\end{abstract}

Keywords: FSC, Forest Management, ISO 38200, PEFC.

\section{Abstrak}

Tujuan dari penelitian ini adalah untuk mengetahui pengaruh pengelolaan hutan FSC Chain of Custody, PEFC Sustainable Forest Management dan ISO 38200 Chain of custody kayu dan produk berbasis kayu terhadap kinerja bisnis industri kayu di Indonesia indikator kinerja yaitu kepuasan Pelanggan, peningkatan penjualan dan produktivitas. Penelitian ini dilakukan di beberapa perusahaan yang mengolah kayu atau menggunakan kayu sebagai bahan utama di Indonesia dengan 400 responden. Responden adalah karyawan industri kayu sebagai manajemen puncak, manajer dan staf yang memiliki planor telah menerapkan FSC, PEFC dan ISO 38200. Latar belakang penelitian ini adalah karena kurangnya penelitian PEFC, FSC dan ISO 38200 pada kayu di Indonesia. Pengumpulan data dilakukan dengan mendistribusikan kuesioner online elektronik pada Agustus hingga November 2019 dan menganalisis pemrosesan data menggunakan Structural Equation Model (SEM) dan software Linear Structural Model (LISREL) versi 8.70. Hasil analisis menunjukkan bahwa FSC Chain of Custody, PEFC Sustainable Forest Management dan ISO 38200 Chain of custody dari kayu dan berbahan dasar kayu mempengaruhi bisnis secara signifikan dan positif seperti peningkatan kepuasan pelanggan, Peningkatan penjualan dan peningkatan produktivitas.

Kata Kunci: FSC, ISO 38200, PEFC, Pengelolaan Hutan. 


\section{JURNAL TENGKAWANG (2020) \\ Vol. 10 (1): 34 - 44}

\section{PENDAHULUAN}

Menurut World Wildlife Fund bahwa hutan mencakup lebih dari 30\% permukaan tanah Bumi, daerah hutan ini dapat menyediakan makanan, obatobatan dan bahan bakar untuk lebih dari satu miliar orang. Indonesia memiliki tanah seluas 187,7 juta ha, terdiri dari hutan seluas 93,9 juta ha. Area lahan tertutup kawasan hutan terdiri dari: 85,85 juta ha $(45,7 \%)$ masih berhutan dan 34,54 juta ha $(18,4 \%)$ adalah lahan tidak berhutan (non-hutan). Deforestasi Indonesia pada 2016-2017 adalah 0,48 juta ha (di dalam dan di luar kawasan hutan), yang merupakan deforestasi besar seluas 0,66 juta ha dikurangi dengan reboisasi 0,18 juta ha. Tingkat deforestasi untuk periode 2011-2017 adalah hasil dari perhitungan deforestasi bersih yang sudah mempertimbangkan kegiatan reboisasi. Sedangkan perhitungan pada periode sebelumnya masih menggunakan deforestasi bruto. Pada periode 2014-2015, 30\% deforestasi terjadi di kawasan kebakaran hutan dan lahan (Dephut, 2019)

Tujuan dari pemantauan sumber daya hutan adalah untuk mengurangi deforestasi yang tidak direncanakan, memulihkan dan merehabilitasi hutan terdegradasi, pengelolaan hutan berkelanjutan, dan mengevaluasi fungsi penyerapan karbon oleh hutan, lahan berhutan dan pohon di luar hutan untuk memoderasi iklim global (Fujita, 2010). Tujuan penerapan FSC, PEFC adalah untuk melindungi hutan tropis menjadi semakin mendesak karena penurunan wilayah hutan sebesar $6 \%$ dan $17 \%$ emisi karbon dioksida global (Baccini et al., 2012). Sangat diperlukan cara-cara untuk mengurangi kehilangan hutan dan mempertahankan cadangan oksigen (Brown, 2013; Sills, et al., 2014; Lee et al., 2018). Sebagian besar hutan menjadi deforestasi dan degradasi hutan yang tinggi (Sloan dan Sayer, 2015). Deforestasi berkontribusi besar terhadap peningkatan emisi gas rumah kaca global dan menghasilkan perubahan iklim (Harris et al., 2012). Banyak orang yang tinggal di hutan atau dekat hutan ini sangat bergantung pada sumber daya hutan dan mata pencaharian mereka terancam oleh deforestasi (Sunderlin et al., 2005). Newsom \& Hewitt (2005) meneliti dan menemukan bahwa $91 \%$ perusahaan bersertifikat diharuskan meningkatkan pelatihan pekerjanya, 82\% meningkatkan keselamatan, dan sebanyak $64 \%$ meningkatkan upah pekerja. Hirschberger Research (2005) sebanyak 183 dari 12 perusahaan hutan Rusia yang disertifikasi dengan luas total lebih dari 3,5 juta ha menemukan bahwa hasil sertifikasi hutan memperkuat hak kerja bagi pekerja perusahaan hutan. Maria Tysiachniouk (2005) meneliti sebagian besar perusahaan regional bersertifikat hutan karena perlindungan pekerja meningkat dan penundaan gaji menurun. Pekerja memahami bahwa sertifikasi dapat digunakan sebagai alat perlindungan sosial.

Ada banyak perusahaan yang memiliki sertifikat pengelolaan hutan, pada tahun 2019 sebanyak perusahaan di Indonesia yang telah bersertifikat sebanyak 580 (FSC.org, 2019). Banyak perusahaan yang bersertifikat hutan pada 2019, tujuan utama penerapan FSC, 


\section{JURNAL TENGKAWANG (2020) \\ Vol. 10 (1): 34 - 44}

PEFC dan ISO 38200: 2018 adalah untuk memenuhi peraturan pemerintah dan juga permintaan dari pelanggan, ada beberapa tujuan yang ingin dicapai yaitu meningkatkan kinerja bisnis seperti pelanggan indeks kepuasan, meningkatkan penjualan, meningkatkan produktivitas dan keselamatan dan kepuasan karyawan. Tujuan dari penelitian ini adalah untuk mengetahui pengaruh pengelolaan hutan FSC Chain of Custody, PEFC Sustainable Forest Management dan ISO 38200 Chain of custody kayu dan produk berbasis kayu terhadap kinerja bisnis industri kayu di Indonesia. Tujuan dari penelitian ini adalah untuk mengetahui pengaruh pengelolaan hutan FSC Chain of Custody, PEFC Sustainable Forest Management dan ISO 38200 Chain of custody kayu dan produk berbasis kayu untuk kinerja bisnis industri kayu di Indonesia. Pembaharuan dari penelitian ini adalah studi pertama yang menganalisis pengaruh FSC, PEFC dan ISO 38200 di Indonesia.

\section{METODE PENELITIAN}

Analisis data penelitian ini menggunakan Structural Equation Model (SEM) menggunakan Linear Structural Model (LISREL) versi 8.70. William dan Gavin (2004) menggunakan LISREL untuk menguji hubungan antara variabel laten dan indikator - indikator dan konstruk tersebut memiliki reliabilitas yang baik adalah jika nilai Construct Reliability $(\mathrm{CR}) \geq 0,70$ dan variance extracted values $\geq 0.50$.

Data penelitian ini didasarkan pada kuesioner yang disebar di 417 responden dari 20 industri kayu di Indonesia yang memiliki rencana atau telah menerapkan manajemen FSC Chain of Custody, PEFC Sustainable Forest Management dan ISO 38200 Chain of custody kayu dan produk berbasis kayu. Berdasarkan penelitian sebelumnya dan tujuan penulisan penelitian ini model penelitian sebagai berikut:

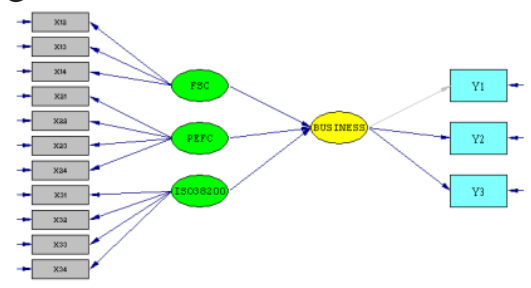

\section{Gambar 1 Model Penelitian}

Berdasarkan model penelitian pada gambar diatas hipotesis sebagai berikut:

1. H1 : Ada hubungan yang signifikan dan positif antara penerapanFSC (X1)dengan Kinerja Industri Kayu (Y).

2. H2 : Ada hubungan yang signifikan dan positif antara penerapan PEFC (X2) dengan Kinerja Industri Kayu (Y).

3. H3 : Ada hubungan yang signifikan dan positif antara penerapan ISO 38200 (X3) dengan Kinerja Industri Kayu (Y).

Berdasarkan hipotesis indikator indikator variabel yang digunakan dalam penelitian ini adalah indikator utama variabel independen FSC (X1) yaitu Sistem Manajemen (X12), Material Sourcing \& Handling (X13), Volume Control (X14) (FSC.org, 2019). Indikator utama variabel PEFC (X2) adalah Kepemimpinan (X21), Perencanaan \& Dukungan (X22), Evaluasi Kinerja (X23), Peningkatan (X24). (PEFC.org, 2019). Indikator utama ISO 38200 (X3) adalah 
Persyaratan Organisasi (X31), Penilaian Risiko (X32), Metode Pengendalian Chain of Custody (X33), Informasi Keluaran (X34) (ISO.org, 2019). Indikator utama variabel dependen dari Kinerja (Y) adalah Kepuasan Pelanggan (Y1), Peningkatan Penjualan (Y2), Produktivitas (Y3).

Tabel 1 Profil Responden

\begin{tabular}{cccccccc}
\hline \multirow{2}{*}{ Pulau } & $\begin{array}{c}\text { Laki-laki } \\
\text { Manajemen } \\
\text { Puncak }\end{array}$ & Manajer & Staff & $\begin{array}{c}\text { Manajemen } \\
\text { Puncak }\end{array}$ & Manajer & Staff & Total \\
\hline Sumatra & 11 & 17 & 21 & 8 & 12 & 12 & 79 \\
Jawa & 24 & 31 & 23 & 9 & 23 & 18 & 117 \\
Kalimantan & 13 & 18 & 14 & 8 & 9 & 8 & 70 \\
Sulawesi & 8 & 17 & 9 & 4 & 9 & 11 & 58 \\
Bali & 6 & 10 & 9 & 5 & 9 & 9 & 48 \\
Papua & 5 & 7 & 3 & 2 & 4 & 4 & 25 \\
\hline
\end{tabular}

Langkah pertama adalah membuat program sintaks pada software Lisrell setelah itu program dijalankan untuk mendapatkan faktor pemuatan variabel independen FSC (X1) yaitu Sistem Manajemen (X12), Material Sourcing \& Handling (X13), Volume Control (X14) (FSC.org, 2019). Indikator utama variabel PEFC (X2) adalah Kepemimpinan (X21), Perencanaan \& Dukungan (X22), Evaluasi Kinerja (X23), Peningkatan (X24). (PEFC.org, 2019). Indikator utama ISO 38200 (X3) adalah Persyaratan Organisasi (X31), Penilaian Risiko (X32), Metode Pengendalian Chain of Custody (X33), Informasi Keluaran (X34) (ISO.org, 2019). Indikator utama variabel dependen dari Daya Saing Bisnis (Y) adalah Kepuasan Pelanggan (Y1), Peningkatan Penjualan (Y2), Produktivitas (Y3). Analisis data dilakukan oleh Structural Equation Model (SEM) menggunakan Linear
Penelitian ini dilakukan di beberapa industri kayu yang mengolah kayu atau menggunakan kayu sebagai bahan utama di Indonesia dengan 417 responden. Respondenterdiri dari karyawan industri kayu sebagai manajemen puncak, manajer dan staf yang memiliki planor yang telah menerapkan FSC, PEFC dan ISO 38200.
Structural Model (LISREL) versi 8.70 dari Joreskog dan Sorbom (2008).

\section{HASIL DAN PEMBAHASAN}

Berdasarkan hasil pengolahan data menggunakan software Lisrell didapatkan hasil sebagai berikut:

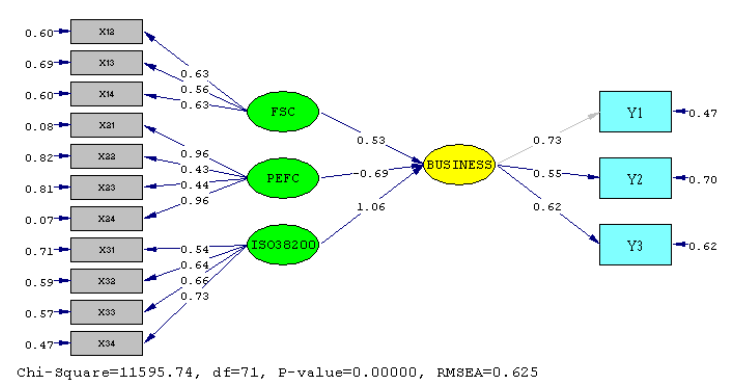

Gambar 3. Nilai Indikator

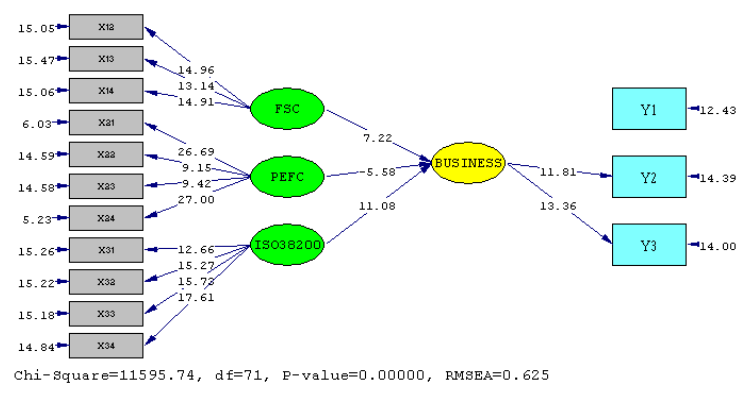




\section{Gambar 4. Indikator t-Value}

Berdasarkan gambar 3 dan gambar 4 dapat disimpulkan bahwa tidak ada varians error nilai negatif, dan nilai loading faktor FSC, PEFC dan ISO 38200 di atas $0,5(>0,5)$ dan nilai t dari loading faktor lebih besar dari 1,96 (> 1,96). Ini adalah semua indikator valid dan signifikan.

Tabel 2 Hasil Indikator Analisis Orde

\begin{tabular}{|c|c|c|c|c|}
\hline Variabel & Indikators & $\begin{array}{l}\text { Pemuatan } \\
\text { Faktor }\end{array}$ & $\begin{array}{c}T- \\
\text { Value }\end{array}$ & Keterangan \\
\hline \multirow{4}{*}{ FSC ( X1) } & Sistem Manajemen (X12) & 0.63 & 14.96 & Valid \& Sig \\
\hline & $\begin{array}{c}\text { Sumber\&Penanganan Material } \\
\text { (X13) }\end{array}$ & 0.56 & 13.14 & Valid \& Sig \\
\hline & Kontrol Volume (X14) & 0.63 & 14.91 & Valid \& Sig \\
\hline & Kepemimpinan (X21) & 0.96 & 26.69 & Valid \& Sig \\
\hline \multirow{3}{*}{ PEFC (X2) } & $\begin{array}{c}\text { Perencanaan\&Dukungan } \\
\text { (X22) }\end{array}$ & 0.43 & 9.15 & Valid \& Sig \\
\hline & Evaluasi Kinerja (X23) & 0.49 & 9.42 & Valid \& Sig \\
\hline & Perbaikan (X24) & 0.95 & 27.10 & Valid \& Sig \\
\hline \multirow[b]{3}{*}{$\begin{array}{l}\text { ISO } 38200 \\
(\mathrm{X3})\end{array}$} & Persyaratan Organisasi (X31) & 0.54 & 12.66 & Valid \& Sig \\
\hline & Resiko Tugas (X32) & 0.64 & 15.27 & Valid \& Sig \\
\hline & $\begin{array}{l}\text { Metode Kontrol Chain of } \\
\text { Custody (X33) }\end{array}$ & 0.66 & 15.71 & Valid \& Sig \\
\hline \multirow{4}{*}{$\begin{array}{l}\text { Daya Saing Bisnis } \\
\text { ( Y) }\end{array}$} & Informasi Luar (X34) & 0.73 & 17.61 & Valid \& Sig \\
\hline & Kepuasan Pelanggan (Y1) & 0.73 & 14.43 & Valid \& Sig \\
\hline & Peningkatan Penjualan (Y2) & 0.55 & 14.39 & Valid \& Sig \\
\hline & Produktifitas (Y3) & 0.62 & 14.10 & Valid \& Sig \\
\hline
\end{tabular}

\section{Kedua CFA Membangun Validitas}

Semua area memuat faktor yang valid dan signifikan. Variabel independen FSC (X1) adalah Sistem Manajemen (X12), Pengadaan \& Penanganan Material (X13), Kontrol Volume (X14) (FSC.org, 2019). Indikator utama variabel PEFC (X2) adalah Kepemimpinan (X21), Perencanaan \& Dukungan (X22), Evaluasi Kinerja (X23), Peningkatan (X24). (PEFC.org, 2019). Indikator utama ISO 38200 (X3) adalah Persyaratan Organisasi (X31), Penilaian Risiko (X32), Metode Pengendalian Chain of Custody (X33), Informasi
Keluaran (X34) (ISO.org, 2019). Indikator utama variabel dependen dari Daya Saing Bisnis (Y) adalah Kepuasan Pelanggan (Y1), Peningkatan Penjualan (Y2), Produktivitas (Y3).

Hasil ini dapat disimpulkan bahwa Chain of Custody FSC, PEFC Sustainable Forest Management dan ISO 38200 Chain of custody kayu dan produk berbasis kayu valid dan signifikan. Hasil validitas juga diperkuat oleh nilai ChiSquare (r) yang menghasilkan nilai 11595,74. Langkah selanjutnya adalah menghitung nilai Construct Reliability (CR) dan Value of variance entrance (VR) pada tabel 4. 
Tabel 4 Hasil Analisis Orde Kedua Membangun Reliabilitas

\begin{tabular}{lcrrrr}
\hline \multicolumn{1}{c}{ Indikator } & $\begin{array}{c}\text { Loading } \\
\text { Faktor }\end{array}$ & $\begin{array}{c}\text { Loading } \\
\text { Faktor2 }\end{array}$ & $\begin{array}{c}\text { I-Loading } \\
\text { Faktor2 }\end{array}$ & CR & VE \\
\hline Sistem Manajemen (X12) & 0.63 & 0.40 & 0.60 & \\
Sumber \& Penanganan Material (X13) & 0.56 & 0.31 & 0.69 & \\
Kontrol Volume (X14) & 0.63 & 0.40 & 0.60 & \\
Kepemimpinan (X21) & 0.96 & 0.92 & 0.08 & \\
Perencanaan \& Dukungan (X22) & 0.43 & 0.18 & 0.82 & \\
Evaluasi Kinerja (X23) & 0.49 & 0.24 & 0.76 & \\
Perbaikan (X24) & 0.95 & 0.90 & 0.10 & \\
Persyaratan Organisasi (X31) & 0.54 & 0.29 & 0.71 & 0.87 & \multirow{2}{*}{0.73} \\
Resiko Tugas (X32) & 0.64 & 0.41 & 0.59 & \\
Metode Kontrol Chain of Custody & 0.66 & & & \\
(X33) & & 0.44 & 0.56 & \\
Informasi Luar (X34) & 0.73 & 0.53 & 0.47 & \\
Kepuasan Pelanggan (Y1) & 0.73 & 0.53 & 0.47 & \\
Peningkatan Penjualan (Y2) & 0.55 & 0.30 & 0.70 & \\
Produktifitas (Y3) & 0.62 & 0.38 & 0.62 & \\
\hline
\end{tabular}

Berdasarkan perhitungan rumus $\mathrm{CR}$ konstruksi reliabilitas diperoleh hasil dan indikator adalah $0,87(\mathrm{CR}) \geq 0,70$ dan $0,73(\mathrm{VE}) \geq 0,50$ dan disimpulkan bahwa semua indikator memiliki reliabilitas yang baik dan konstruk nilai memiliki reliabilitas yang baik. Oleh karena itu, berdasarkan hasil analisis uji reliabilitas dapat disimpulkan bahwa reliabilitas seluruh indikator merupakan indikator yang baik dan dapat disimpulkan bahwa penelitian memenuhi persyaratan. Langkah selanjutnya adalah melaksanakan Analisis Goodness of Fit ( GOF), data GOF diperoleh dari hasil eksekusi software.

\section{AnalisisGoodness Of Fit (GOF)}

Uji kebaikan dan kesesuaian model pada keseluruhan model fit tentang analisis nilai GOF statistik yang dihasilkan oleh program lisrel, untuk relevansi model (model fit) yang cukup baik dan untuk modelnya sesuai dengan kriteria seperti yang ditunjukkan pada Tabel 5.

Tabel 5. Goodness Of Fit

\begin{tabular}{cccc}
\hline Indeks Fit & Nilai & Standar Nilai & Keterangan \\
\hline Chi-Square & 11595.72 & $>0.5$ & Fit \\
Root Mean Square Error of Approximation (RMSEA) & 0.05 & $<0.08$ & Fit \\
Index of Normed Fit (NFI) & 0.91 & $>0.90$ & Fit \\
Index of Non-Normed Fit (NNFI) & 0.91 & $>0.90$ & Fit \\
Index of Comparative Fit (CFI) & 0.92 & $>0.90$ & Fit \\
Index of Incremental Fit(IFI) & 0.91 & $>0.90$ & Fit \\
Index of Relative Fit (RFI) & 0.91 & $>0.90$ & Fit \\
Goodness of Fit Index (GFI) & 0.91 & $>0.90$ & Fit \\
\hline
\end{tabular}


Berdasarkan hasil analisis dapat disimpulkan bahwa semua indikator sudah fit dan dapat disimpulkan bahwa keseluruhan model masih cocok. Model persamaan (Structural Equations) linier dari 8.70 perangkat lunak LISREL diperoleh sebagai berikut:

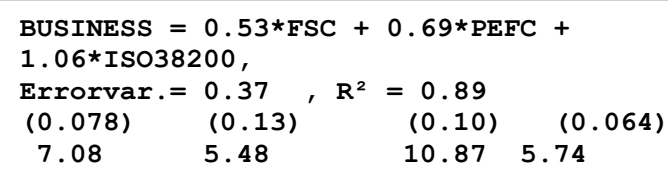

Gambar 4 Persamaan Struktural

Berdasarkan hasil analisis dapat dilihat bahwa FSC pengelolaan hutan, PEFC dan ISO38200 berpengaruh positif dan signifikan terhadap kinerja industri kayu. Dengan nilai $\mathrm{t}$ sama dengan 7.08. Model goodness of fit diproduksi cukup baik dengan nilai chisquare 11595,74. Demi kebajikan kriteria fit. Nilai R Square 0,89 berarti implementasi FSC, PEFC dan ISO 38200 telah mempengaruhi kinerja industri kayu sebesar $89 \%$ sementara faktor-faktor lain mempengaruhi $11 \%$. Jadi dapat disimpulkan dan diperoleh persamaan regresi berikut (Kinerja Industri Kayu $)=\mathbf{0 , 5 3} *$ FSC + 0,69* PEFC + 1,06* ISO38200 + Errorvar. KESIMPULAN

Berdasarkan analisis hasil penelitian dapat disimpulkan bahwa penerapan FSC Chain of Custody, PEFC Sustainable Forest Management dan ISO 38200 Chain of custody kayu dan produk berbasis kayu memiliki dampak positif dan signifikan terhadap kinerja industri kayu seperti meningkatkan indeks kepuasan pelanggan, meningkatkan penjualan dan meningkatkan produktivitas sehingga akan meningkatkan laba perusahaan. Objek penelitian tidak hanya di Indonesia tetapi juga dapat diperluas ke negara lain. Hasil penelitian ini implementasi FSC Chain of Custody, PEFC Sustainable Forest Management dan ISO 38200 Chain of custody sistem manajemen produk berbasis kayu dan memiliki pengaruh pada kinerja bisnis perusahaan sehingga perusahaan yang belum mengimplementasikannya dapat direkomendasikanuntuk segera menerapkan FSC Chain of Custody, PEFC Sustainable Forest Management dan ISO 38200 Chain of custody kayu dan produk berbasis kayu, studi ini memperkuat hasil penelitian sebelumnya. Purwanto dkk. (2019) menyatakan bahwa pengelolaan hutan berpengaruh signifikan dan positif terhadap kinerja bisnis. Santoso et al. (2019) menyatakan bahwa FSC pengelolaan hutan berpengaruh signifikan dan positif terhadap kinerja bisnis.

Studi ini berkontribusi pada penelitian tentang manfaat FSC Chain of Custody, PEFC Sustainable Forest Management dan ISO 38200 Chain of custody sertifikasi produk kayu dan produk berbahan dasar kayu. Keterbatasan penelitian ini adalah tidak membahas tentang indikator kinerja keuangan, jadi dalam penelitian masa depan, indikator kinerja keuangan dapat 


\section{JURNAL TENGKAWANG (2020) \\ Vol. 10 (1): 34 - 44}

diukur selama periode waktu tertentu. Selain itu, perbandingan kinerja keuangan FSC Chain of Custody, PEFC Sustainable Forest Management dan ISO 38200 Chain of custody kayu dan produk kayu pemegang Sertifikat dapat dibuat. FSC Chain of Custody, PEFC Sustainable Forest Management dan ISO 38200 Chain of custody kayu dan produk-produk berbahan dasar kayu berlaku untuk semua organisasi yang memperdagangkan, memproses atau memproduksi kayu dan produk hutan. Manfaat penerapan FSC Chain of Custody, PEFC Sustainable Forest Management dan ISO 38200 Chain of custody kayu dan sertifikasi produk berbahan dasar kayu yaitu mempertahankan pelanggan yang merupakan manfaat utama sertifikasi, meningkatkan pelanggan baru, meningkatkan ekspor, meningkatkan citra perusahaan, meningkatkan laba, komitmen terhadap tanggung jawab lingkungan yang meningkatkan citra perusahaan, mempromosikan, penggunaan sumber daya hutan secara berkelanjutan, meningkatkan komunikasi dengan pelanggan, mencegah pembalakan liar, dan meningkatkan efisiensi pengelolaan.

Hasil penelitian menunjukkan bahwa FSC Chain of Custody, PEFC Sustainable Forest Management dan ISO 38200 Chain of custody kayu dan sertifikasi produk berbahan dasar kayu merupakan prasyarat untuk kinerja dan daya saing bagi perusahaan. Salah satu manfaat dari penelitian ini adalah untuk meyakinkan pemilik kayu dan perusahaan pengolahan untuk mendapatkan FSC Chain of Custody, PEFC Sustainable Forest Management dan ISO 38200 Chain of custody kayu dan produk-produk berbahan dasar kayu bersertifikat karena manfaat dari penerapannya telah diuji dan juga sebagai bentuk kepatuhan terhadap hukum dan peraturan sehingga dapat meningkatkan citra baik perusahaan.

Penelitian ini memiliki beberapa keterbatasan, sampel tidak mewakili populasi target, jumlah sampel yang tidak banyak karena waktu dan biaya yang terbatas, objek penelitian ini hanya perusahaan industri di Indonesia. Keterbatasan waktu penelitian dan jumlah responden yang hanya 417 responden belum meyakinkan untuk menggeneralisasi hasil penelitian. Sofware yang digunakan untuk analisis data adalah Lisrel dan banyak orang belum mengenal software ini. Studi ini tidak membahas beberapa indikator keuangan sehingga tidak dapat diketahui manfaat finansial nyata dari penerapan FSC Chain of Custody, PEFC Sustainable Forest Management dan ISO 38200 Chain of custody kayu dan produk berbahan dasar kayu, pada penelitian berikutnya membahas tentang indikator keuangan dengan membandingkan kondisi keuangan FSC Chain of Custody, PEFC Sustainable Forest Management dan ISO 38200 Chain of custody kayu dan produk berbahan dasar kayu perusahaan bersertifikat dan tidak bersertifikat. Penelitian ini hanya meneliti industri kertas meskipun banyak perusahaan yang menerapkan FSC Chain of Custody, PEFC Sustainable Forest Management dan ISO 38200 Chain of custody kayu dan produk-produk berbahan dasar kayu seperti distributor kayu, pabrik kayu dan lain-lain. Untuk penelitian lebih lanjut, disarankan untuk memeriksa perusahaan 
di seluruh rantai mulai dari kayu hingga pengguna akhir.

\section{DAFTAR PUSTAKA}

Baccini, A., Goetz, S.J., Walker, W.S. (2012). Estimated carbon dioxide emissions from tropical deforestation improved by carbondensity maps. Nat Clim Change. https://doi.org/10.1038/NCLIMA

\section{TE1354}

Brown, H.C, Lassoie, J.P., (2010). Institutional choice and local legitimacy in community-based forest management: lessons from Cameroon. Environ Conserv 37, 261-269.

Brown, M.I. (2013). Redeeming REDD: Policies, Incentives and Social Feasibility For Avoided Deforestation. Earthscan, London. Fujita, K. and Shaw, R. (2010), "Chapter 7 Forest management as an adaptation option in mountain areas

PURWANTO, A., Asbari, M., \& Budi Santoso, P. Wijayanti, L.M, Hyun. C.C (2020). ISO 38200:2018 Benefit and Timber Industries Competitiveness: Rethoric or Reality. JEMA: Journal of Economic, Management and Accounting Adpertisi, 1(1). https://doi.org/10.4536/jr.v1i1.122 .https://ummaspul.ejournal.id/maspuljr/article/view/3 33

Purwanto, A. (2019). Effect of Implementation ISO 38200:2018 Chain of Wood Products Custody Toward Wood Industries Business Competitiveness In Pati Central Java Indonesia, International Journal of Scientific Research in Science and Technology (IJSRST), 6 (6).261-268. Doi:
https://doi.org/10.32628/IJSRST1 96649

Santoso, P, Purwanto, A., \& Asbari, M.(2019). Influence of Implementation Chain of Custody Forest Management System FSCSTD-40-004 V3-0 to Business Performance of Paper Industriesia in Banten Indonesia, International Journal of Management and Humanities (IJMH), 4(4), 32-36. DOI:

https://doi.org/10.35940/ijmh.C04 $\underline{\text { 42D0482.124419 }}$

Purwanto, A., Sihite, B.O., Yanthy, E., Hutagalung, L. (2019). Influence of Forest Management System FSC, PEFC and ISO 38200:2018 Toward Business Performance at Wood and Paper Industries in Sumatera Indonesia, Saudi Journal of Business and Management Studies, 4(12). 892-897. DOI: http://10.36348/sjbms.2019.v04i1 $\underline{2.005}$

Purwanto, A., Asbari, M., \& Santoso, P.(2019). Can ISO 38200:2018 Wood and Wood Based Product Chain of Custody Increase Businesss Competitiveness of Wood Industries in West Java. Jurnal Hutan dan Masyarakat. 8 (2). 113-125.

http://dx.doi.org/10.24259/jhm.v1 $\underline{1 \mathrm{i} 2.8358}$

Harris, N.L., Brown, S., Hagen, S.C., Saatchi, S.S., Petrova, S., (2012). Baseline map of carbon emissions from deforestation in tropical regions. Science 336, 1573-1576.

Hirschberger, Peter (2005): The Effects of FSC-certification in Latvia: an analysis of CARs. WWF Forest Programme.29 p. http://www.panda.org/downloads/ 
forests/fscanalysislatvia.pdf (as of June 2008)

ISO. org, (2019), ISO 38200 Chain of custody of wood and wood-based products,accessed 26 December 2019

Lee, D., Llopis, P., Waterworth, R., Roberts, G., Pearson, T.(2018). Approaches to REDD+Nesting : Lessons Learned from Country Experiences. World Bank, Washington, DC.

Lewis, R.A., Davis, S.R.(2015). Forest certification, institutional capacity, and learning: an analysis of the impacts of the Malaysian Timber Certification Scheme. For. Pol. Econ. 52, 18-26. Maletz, O., Tysiachniouk,

Newsom, Deanna and Hewitt, Daphne (2005): The Global Impacts of SmartWood Certification. Final Report ofthe TREES Program for the Rainforest Alliance. http://www.rainforestalliance.org/ programs/forestry/perspectives/do cuments/sw_impacts.pdf (as of June 2008)

Pinto, L.F.G., McDermott, C.L., (2013). Equity and forest certification - a case study in Brazil. For. Pol. Econ. 30, 23-29.

PEFC.org, (2019), PEFC Sustainable Forest Management, accessed 26 December 2019 Renström, Margareta and Rainey, Margaret (WWF Sweden) (2001): Social issues and the Forestry StewardshipCouncil. Sustainable Development International 4,137139.

http://www.p2pays.org/ref/40/397 69.pdf (as ofJune 2008)160 RosTonen, Mirjam
Santoso, P, Purwanto, A., \& Asbari, M.(2019). Influence of Implementation Chain of Custody Forest Management System FSCSTD-40-004 V3-0 to Business Performance of Paper Industriesia in Banten Indonesia, International Journal of Management and Humanities (IJMH), 4(4), 32-36. DOI: https://doi.org/10.35940/ijmh.C04 42D0482.124419

Sunderlin, W.D., Angelsen, A., Belcher, B., Burgers, P., Nasi, R., et al., (2005). Livelihoods, forests, and conservation in developing countries: an overview. World Dev. 33, 1383-1402.

Sunderlin, W.D., Hatcher, J., Liddle, M., (2008). From Exclusion to Ownership? Challengesand Opportunities

Sloan, S., Sayer, J.A., (2015). Forest Resources Assessment of 2015 shows positive global trends but forest loss and degradation persist in poor tropical countries. For. Ecol. Manage. 352, 134-145.

Sills, E.O., Atmadja, S.S., de Sassi, C., Duchelle, A.E., Kweka, D.L., Resosudarmo, I.A.P., Sunderlin, W.D. (Eds.), (2014). REDD+ On the Ground: a Case Book of Subnational Initiatives Across the Globe. CIFOR, Bogor, Indonesia

Tysiachniouk, Maria (2005): Forest Certification in Russia. (Center for Independent Social Research St. Petersburg, Russia); Paper presented at Yale Forest Certification Symposium. published by Yale school of forestry \&environmentalstudies.http://ww w.yale.edu/forestcertification/sym 
JURNAL TENGKAWANG (2020)

Vol. 10 (1): 34 - 44

posium/pdfs/Book\%20Chapters/1

2\%20Russia.pdf (as of June 2008)

Williams, Gavin (2004) "Structural

Equation Modeling Methods In

Strategy Research: Application and Issue" Research Methodology in Strategy and Management

(Research Methodology in Strategy and Management, Vol. 1), Emerald Group Publishing Limited, Bingley, pp. 303-346.

https://doi.org/10.1016/S1479-

8387(04)01111-7 